\title{
Electrical Tree Growth and Partial Discharge in Epoxy Resin Under Combined AC and DC Voltage Waveforms
}

DOI:

10.1109/TDEI.2018.007310

\section{Document Version}

Accepted author manuscript

Link to publication record in Manchester Research Explorer

\section{Citation for published version (APA):}

Rowland, S., Iddrissu, I., Zheng, H., Lv, Z., \& Schurch Brandt, R. (2018). Electrical Tree Growth and Partial

Discharge in Epoxy Resin Under Combined AC and DC Voltage Waveforms. IEEE Transactions on Dielectrics and Electrical Insulation, 25(6), 2183-2190. https://doi.org/10.1109/TDEI.2018.007310

\section{Published in:}

IEEE Transactions on Dielectrics and Electrical Insulation

\section{Citing this paper}

Please note that where the full-text provided on Manchester Research Explorer is the Author Accepted Manuscript or Proof version this may differ from the final Published version. If citing, it is advised that you check and use the publisher's definitive version.

\section{General rights}

Copyright and moral rights for the publications made accessible in the Research Explorer are retained by the authors and/or other copyright owners and it is a condition of accessing publications that users recognise and abide by the legal requirements associated with these rights.

\section{Takedown policy}

If you believe that this document breaches copyright please refer to the University of Manchester's Takedown Procedures [http://man.ac.uk/04Y6Bo] or contact uml.scholarlycommunications@manchester.ac.uk providing relevant details, so we can investigate your claim.

\section{OPEN ACCESS}




\title{
Electrical Tree Growth and Partial Discharge in Epoxy Resin Under Combined AC and DC Voltage Waveforms
}

\author{
Ibrahim Iddrissu, Simon M Rowland, Hualong Zheng and Zepeng Lv \\ School of Electrical and Electronic Engineering \\ The University of Manchester \\ Manchester, M13 9PL UK \\ Roger Schurch \\ Universidad Técnica Federico Santa María \\ Departamento de Ingeniería Eléctrica \\ Valparaíso, Chile
}

\begin{abstract}
The effect of DC bias on electrical tree growth and partial discharge (PD) characteristics in epoxy resin (Araldite LY ${ }^{\circledR}$ 5052/Aradur ${ }^{\circledR}$ HY 5052 supplied by Huntsman) is investigated using three waveforms: $\mathrm{AC}, \mathrm{AC}$ with positive $\mathrm{DC}$ bias, and AC with negative DC bias. Needle-plane samples are used. Tree growth is shown to be accelerated by the combined effect of $\mathrm{DC}$ and $50 \mathrm{~Hz} \mathrm{AC}$, beyond the AC growth rate. Positive and negative DC biased tests result in $62 \%$ and $54 \%$ reductions in average time to breakdown, respectively. Different tree structures and stages of development are associated with different partial discharge characteristics, with thick dark tree branches associated with high PD magnitudes, whereas fine tree channel growth is linked with PD magnitudes below 1 pC. AC tests showed five distinct stages of tree growth compared to four stages seen in DC biased tests. In particular, trees growing in the 'reverse direction' from the planar to the point electrode, which is observed in the latter stages of AC tests, is not seen in the DC biased tests. It is concluded that for composite voltages, the $\mathrm{AC}$ component is the essential driver of tree growth but the $\mathrm{DC}$ component can accelerate propagation. AC noise may therefore compromise the reliability of insulation in HVDC networks.
\end{abstract}

Index Terms - Epoxy resin, AC, DC, electrical treeing, space charge, composite waveforms.

\section{INTRODUCTION}

ELECTRICAL treeing is an important precursor to high voltage insulation failure. Electrical trees are gaseous channel defects of micrometre diameter which initiate from locations of high divergent electrical stress [1] and are associated with partial discharges [2]. Partial discharge (PD) behavior, has been shown to reflect tree growth characteristics, with new growth occurring at those parts of the tree in which the partial discharges are visible [3]. Energy associated with PDs has been linked to the rate of channel erosion and degraded volume of the insulation [4]. Phase-resolved PD patterns have also been related to growth characteristics. For example triangular and wing-like patterns are associated with long and narrow tree channels, typical of discharges in a branch type tree, whereas patterns described as turtle-like or rabbit-like are related to discharges in voids [2, 5]. The authors' study of early stage tree growth [6] showed that PD

Manuscript received on 4 January 2018, in final form 8 April 2018, accepted 8 April 2018. Corresponding author: I. Iddrissu. patterns change with tree growth, and can be regarded as combinations of wing-like and turtle-like patterns. PDs associated with the wing-like pattern were considered responsible for the growth of tree length. Electrical treeing is field driven [7], with initiation times, propagation rate, tree shape, and final breakdown times all being influenced by factors such as frequency and magnitude of the applied waveform [8-9].

Electrical trees are generated readily under $\mathrm{AC}$ voltages [1] whereas under DC a relatively high voltage is required for initiation and propagation [10]. With rapid polarity reversal however, much lower voltages are required, as a result of field modification due to space charge at the metallic needle polymer interface [11]. Saito et al [11] investigated tree initiation in polyethylene, superimposing AC on DC voltages. It was shown that tree initiation required the same magnitude of $\mathrm{AC}$ component irrespective of the DC component. This observation is important in systems where mixed AC and DC voltages are present. An example of this is the case of a high voltage DC transmission system in which insulation will be stressed by mixed AC and DC voltages due to harmonics generated by power electronics in the 
converter [12]. Distorted waveforms (e.g. through harmonic pollution) have been shown to cause reduction of equipment lifetime due to accelerated aging of insulation [13]. Investigations using superimposed harmonic frequencies on the fundamental power frequency in epoxy resin also showed similar results, with the $7^{\text {th }}$ harmonic shown to be most detrimental [14].

In high voltage AC systems harmonic distortion up to about $5 \%$ is tolerated for voltages below $69 \mathrm{kV}$, and $1.5-2.5 \%$ for higher voltages [15]. For HVDC systems, there is no equivalent specification for acceptable levels of harmonic distortion. With increased global dependence on HVDC systems, the impact of DC power quality on the reliability of insulation requires evaluation. If noise or harmonics can be allowed on DC systems without compromising insulation reliability, there will be a potential financial advantage. Alternatively the threat to insulation reliability presented by a loss of power quality needs evaluation.

Thermoplastic and thermosetting polymers are used as insulation throughout HVDC systems, in equipment such as cables, terminations, joints, and converter transformers. In this paper, treeing with $50 \mathrm{~Hz}$ superimposed on positive and negative DC voltages is investigated in epoxy resin. Results show accelerated tree growth and reduction in lifetime in DC biased tests.

\section{EXPERIMENTAL}

\subsection{TEST SAMPLES}

Epoxy resin (LY/HY 5052) samples with embedded Ogura needles were fabricated in the classical point-to-plane fashion. The 'plane' surfaces of the samples were coated with aluminum by vacuum evaporation. The needle tip radius was $3 \mu \mathrm{m}$, and needle tip to plane electrode separation was $2 \mathrm{~mm}$. Details of sample preparation are given in [16].

\subsection{TEST CIRCUIT AND SET-UP}

Figure 1 shows a schematic of the experimental set-up. Tree images were recorded every minute using a monochrome CCD camera (Manta G-504B) with a C-mount telecentric lens; giving a resolution of $2452 \times 2056$ pixels, representing a $6 \mathrm{~mm}$ x $5 \mathrm{~mm}$ image. The voltage source was an HV amplifier driven by an arbitrary waveform generator (AWG-PCI 5421) integrated in a PC from which both the amplifier and the

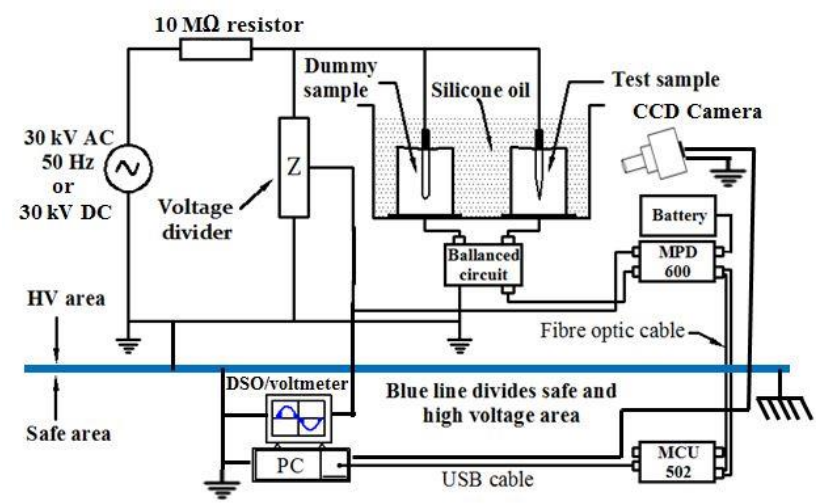

Figure 1. Schematic of experimental set-up for simultaneous imaging of electrical treeing and partial discharge measurement. Equipment above the blue line is housed in an interlocked HV cage.
Table 1. Tree Initiation Using Composite Waveforms

\begin{tabular}{|c|c|c|c|}
\hline \multicolumn{2}{|c|}{ Composite waveforms: $\mathrm{V}(\mathrm{t})=\mathrm{A}+\mathrm{B} \sin \omega(\mathrm{t})$} & \multirow{2}{*}{$\begin{array}{l}\text { Composite } \\
\text { waveform } \\
\text { number }\end{array}$} & \multirow{2}{*}{$\begin{array}{l}\text { Number of } \\
\text { samples } \\
\text { initiated in } \\
\text { this step }\end{array}$} \\
\hline $\begin{array}{c}\text { A: DC Component } \\
(\mathrm{kV})\end{array}$ & $\begin{array}{c}\text { B: AC Component } \\
(\mathrm{kV})\end{array}$ & & \\
\hline 30 & 0 & 1 & 0 \\
\hline 27 & 3 & 2 & 0 \\
\hline 25.2 & 4.8 & 3 & 0 \\
\hline 22.8 & 7.2 & 4 & 0 \\
\hline 21.6 & 8.4 & 5 & 0 \\
\hline 19.8 & 10.2 & 6 & 1 \\
\hline 18.6 & 11.4 & 7 & 0 \\
\hline 17.4 & 12.6 & 8 & 1 \\
\hline 16.8 & 13.2 & 9 & 1 \\
\hline 15.6 & 14.4 & 10 & 2 \\
\hline 15 & 15 & 11 & 5 \\
\hline \multicolumn{4}{|c|}{$\begin{array}{l}\text { For each sample the waveforms formed by combining the signals of columns } 1 \text { and } 2 \\
\text { were applied. These were automatically applied for } 5 \text { minutes each in the numerical } \\
\text { order given in Column } 3 \text {, until a tree initiated. Once a tree was initiated the sample was } \\
\text { removed and the routine started again on a different sample, starting with waveform } 1 \text {. }\end{array}$} \\
\hline
\end{tabular}

image grabbing are controlled.

A balanced circuit was implemented for PD measurement [17] using Omicron's digital detector (MPD 600) in accordance with IEC 60270 [18]. The circuit included a PDfree sample fabricated with a blunt needle. The sensitivity of the system was $0.35 \mathrm{pC}$. Tests were at room temperature with samples immersed in silicone oil to prevent surface discharges.

\subsection{TEST PROCEDURE}

Two groups of tests were carried out using 40 samples. The first set of 10 samples were used to determine the $50 \mathrm{~Hz}$ voltage magnitude which, when superimposed on DC, resulted in tree growth. The remaining 30 samples were used in the second group of tests, in which $\pm 15 \mathrm{kV}$ DC was combined with $15 \mathrm{kV} \mathrm{AC}$ as composite waveform. Previously it was determined that the use of pure $30 \mathrm{kV}$ DC does not result in tree initiation $[16,19]$. However combined $15 \mathrm{kV}$ AC and +15 $\mathrm{kV}$ DC was found always to cause tree initiation in the first group, and so was used in the second test.

Table 1 shows the AC and DC magnitudes used in the first group of tests. The AC component is increased while the DC component is decreased so that the peak value of the combined voltage is always $30 \mathrm{kV}$. The composite waveforms were automatically applied sequentially for 5 minutes each in the order shown in Table 1, to one of the 10 samples until a tree initiated. Once a tree was initiated the test was terminated.

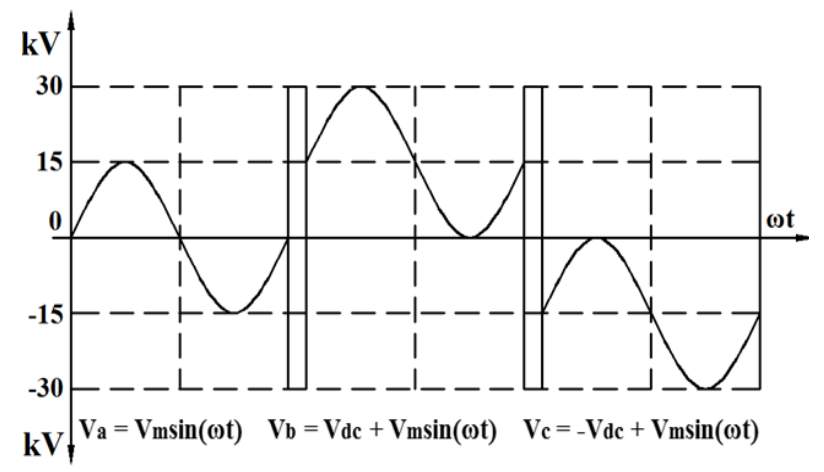

Figure 2. Voltage waveforms used for testing: $\mathrm{Va}=\mathrm{AC}$ at $15 \mathrm{kV}$ peak, $\mathrm{Vb}=\mathrm{AC}$ at $15 \mathrm{kV}$ peak biased at $+15 \mathrm{kV} \mathrm{DC}, \mathrm{Vc}=\mathrm{AC}$ at $15 \mathrm{kV}$ peak biased at $-15 \mathrm{kV}$ DC. 
In the second experiment, all 30 samples had small trees of $\sim 50 \mu \mathrm{m}$ length initiated using an unbiased $\mathrm{AC}$ voltage between 12-16 kVrms. This eliminated variability of initiation seen with DC-dominated tests, and allowed tree growth and breakdown times to be directly compared. This method is described in detail in [10]. These samples, containing small initial trees, were subsequently randomly divided into three groups of 10 samples. The samples from each group were then stressed with waveforms shown in Figure 2 and identified as:

Group a: AC test at $15 \mathrm{kV}$ pk

Group b: Positive DC biased AC (+15 kV DC + $15 \mathrm{kV} \mathrm{AC)}$

Group c: Negative DC biased AC (-15 kV DC + $15 \mathrm{kV} \mathrm{AC)}$

The samples were stressed continuously until either breakdown occurred or, if high levels of damage were seen in the sample without a short circuit, the test was terminated.

\section{TREE INITIATION}

In the geometry used, DC voltages of 60 or $70 \mathrm{kV}$ are required for tree inception if the power quality is high [10]. Thus as expected, at $30 \mathrm{kV} \mathrm{DC}$, when the AC component was zero, trees did not initiate. The earliest sample to initiate did so at $10.2 \mathrm{kV} \mathrm{AC}+19.8 \mathrm{kV}$ DC (running step 6 in Table 1). By step $10,50 \%$ of samples had initiated and the remaining $50 \%$ initiated during waveform number 11 with $15 \mathrm{kV} \mathrm{AC}+15 \mathrm{kV}$ DC. This, and other experience, led to the adoption of the $15 \mathrm{kV} \mathrm{AC}$ and DC voltage components in the second set of tests.

\section{THE VISUAL ASPECT OF TREE GROWTH}

Figure 3 shows typical tree shapes generated in the samples. These are classified into two types:

Forward tree growth (FTG) in which the tree grows from the needle towards the planar electrode, leading to sample failure when the tree fully traverses the insulation. This is a classical tree growth characteristic which consists of an initiation stage, a propagation stage, and finally runaway leading to sample failure [1]. This is observed under both $\mathrm{AC}$ and $\mathrm{AC} \pm \mathrm{DC}$ tests as shown in Figure $3 \mathrm{~A}_{1}$ and $3 \mathrm{~A}_{2}$.

Reverse tree growth (RTG) [20] occurs in some cases after extensive FTG. RTG is visually dominant over the previous FTG and grows from the planar ground electrode towards the needle before the test sample fails. RTG is observed in all 10 samples stressed with $\mathrm{AC}$ only, as shown in Figure $3 \mathrm{~B}_{1}$.

During the FTG process, three distinct tree shapes were observed. Initially thick dark tree channels developed, having either a branch or bush-like tree shape, extending about $300 \mu \mathrm{m}$ from the needle electrode as shown in Figure $3 \mathrm{~A}_{1}$ and $3 \mathrm{~A}_{2}$ respectively. This was followed by an array of fine tree channels extending from the initial dark trees spreading more widely and extending across the insulation. In some cases, on approaching the ground electrode, some of the existing fine tree channels became darkened and widened, leading to sample breakdown. This is shown in Figure $3 \mathrm{~B}_{2}, 3 \mathrm{C}_{2}$ (the image difference between $3 \mathrm{~A}_{2}$ and $3 \mathrm{~B}_{2}$ ) and $3 \mathrm{D}_{2}$. This kind of tree growth characteristic is termed a "bridging tree" by the authors and was observed in all 20 test samples stressed with superimposed AC and DC voltages [20]. Alternatively, on approaching the ground electrode, the fine tree growth may stop growing in length, forming a dark boundary of optically dense tree channels at the furthest extent of the tree parallel to the ground electrode as shown Figure $3 \mathrm{~A}_{1}$. In this case it seems that a few branches from this boundary will bridge to the ground electrode and result in trees growing in the reverse direction as shown in Figure $3 \mathrm{~B}_{1}$. This forward growth characteristic is termed as a 'partially extended tree' and was observed in all 10 samples stressed with AC voltage only [20].

\subsection{TREE GROWTH RATE AND BREAKDOWN}

Figure 4 shows normalized tree length as a function of time for three selected samples with similar breakdown times for $\mathrm{AC}$, and superimposed AC and DC voltages. Each plot is representative of all 10 samples stressed with different voltages. For all 30 samples used in the second group, continuous growth in length and width was observed as shown in Figure $3 \mathrm{~A}_{1}$ and $3 \mathrm{~A}_{2}$. However in samples where the initial incepted tree structures are bush-like, slow growth rates were observed during the initial stages of propagation.

Figure 4 gives examples of the scenario where slow growth was observed in the first 15 minutes of voltage application. After that, samples stressed with superimposed AC and DC

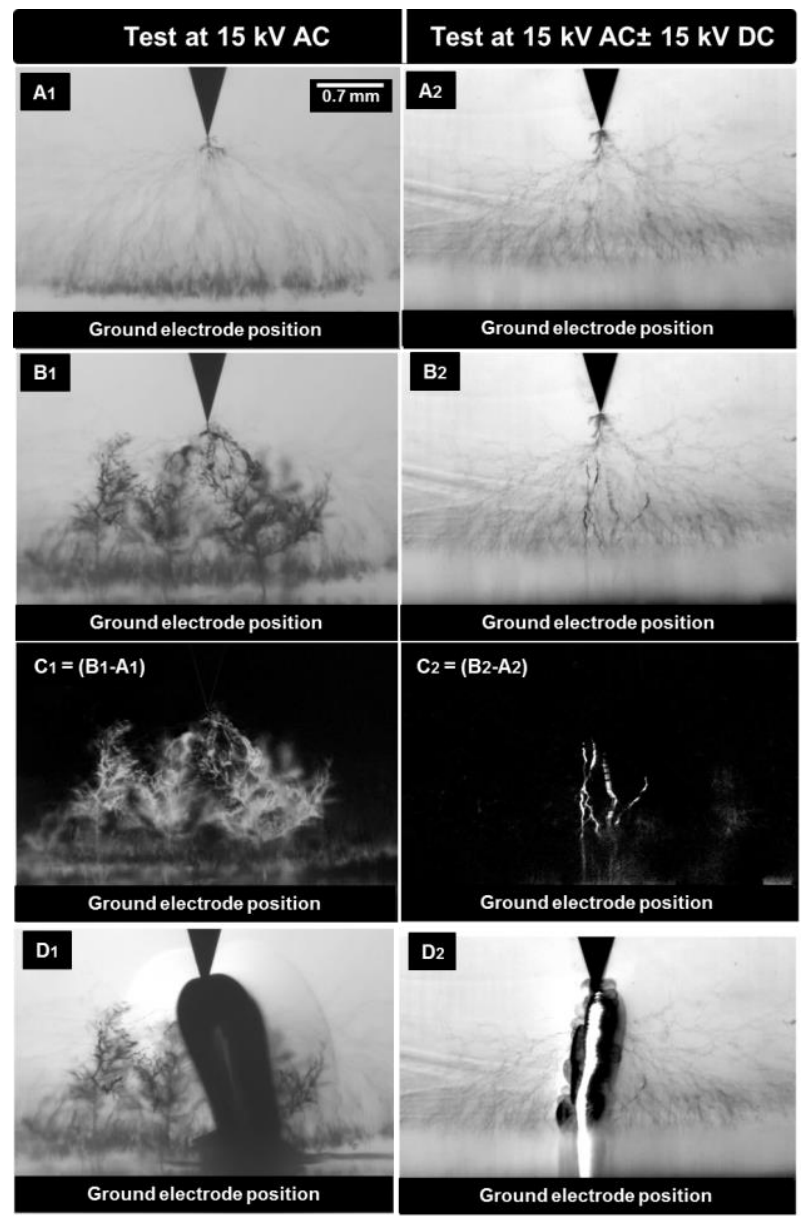

Figure 3. $\mathrm{A}_{1}, \mathrm{~A}_{2}$ : trees growing from needle to plane termed as 'forward tree growth'. $B_{1}$ and $C_{1}$ : trees growing from plane to needle electrode as 'reverse tree growth'. $\mathrm{B}_{2}$ and $\mathrm{C}_{2}$ : darkened and widened bridging tree channels. $\mathrm{D}_{1}$ and $\mathrm{D}_{2}$ : breakdown channels. The $0.7 \mathrm{~mm}$ scale bar applies to all images. Images $C_{i}$ are generated by subtracting $A_{i}$ from $B_{i}$. 


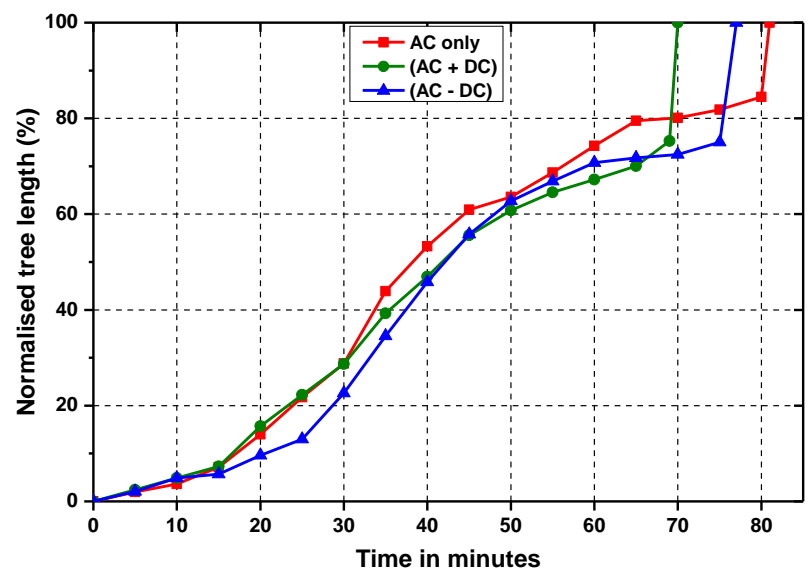

Figure 4. Tree growth under AC, and suprimposed AC and DC for 3

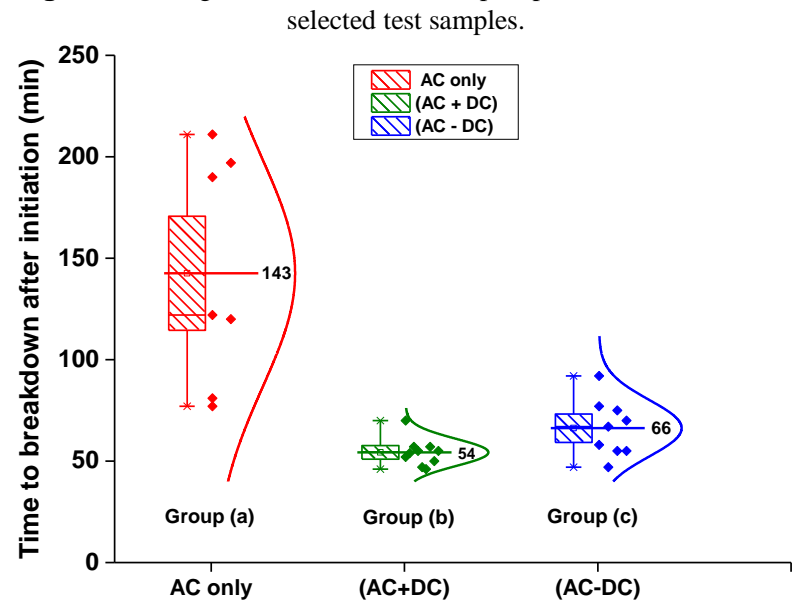

Figure 5. Comparison of treeing breakdown times using $15 \mathrm{kV}$ peak $\mathrm{AC}$, and superimposed $\mathrm{AC}$ and $\mathrm{DC}$ voltages at $30 \mathrm{kV}$ peak.

voltage saw continuous growth up to about $75 \%$ of the needleplane distance, leading to breakdown shortly afterwards. For samples stressed with pure AC, growth in length extended beyond $80 \%$ of the insulation thickness. After that, a period of slow growth was observed prior to the evolution of reverse trees when the fine tree tips became darkened. Breakdown eventually occurred through one of the branching reverse trees. Figure 4 shows similar growth rates throughout the entire process, even with different stresses.

Figure 5 shows the time to breakdown for all samples under the three voltage regimes. AC tests showed a wider distribution of breakdown times and had a longer average time to breakdown of 143 minutes, representing 7 failed samples.

Tests under $\mathrm{AC} \pm \mathrm{DC}$ showed narrower distributions of failure data with an average time to breakdown of 54 minutes and 66 minutes for positive and negative DC biased tests: reductions of $62 \%$ and $54 \%$ respectively. Statistical analysis (Student t-test) from $\mathrm{AC} \pm \mathrm{DC}$ tests shows that there is greater than $95 \%$ chance that the difference between polarities is significant. All samples failed within two hours during AC \pm DC tests whereas under AC only, three samples did not breakdown after four hours. In the latter samples, the experiment was stopped due to substantial damage which turned the samples into semi-carbonized material. It is likely that the $10 \mathrm{M} \Omega$ ballast resistor influenced the survival of these samples by restricting the current.

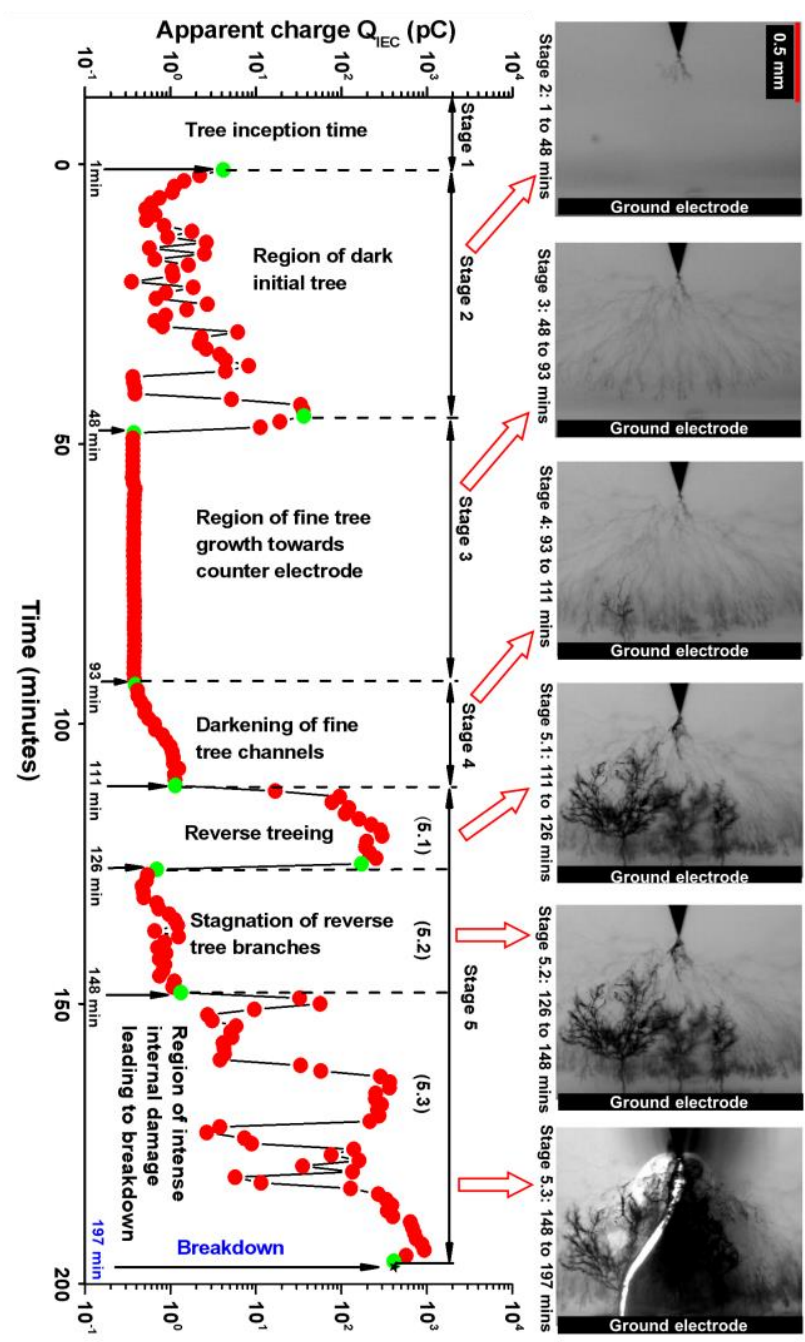

Figure 6. Partial discharge activity during tree growth.

\section{PARTIAL DISCHARGE AND TREE GROWTH}

\subsection{COMMON FEATURES}

Figure 6 shows partial discharge activity during tree growth in a sample between inception and breakdown over a 197 minute period. The first four stages in Figure 6 are representative of the general evolution of discharge activity during tree growth for tests under both $\mathrm{AC}$ and $\mathrm{AC} \pm \mathrm{DC}$ voltages. For AC superimposed on positive or negative DC, the evolution ends in Stage 4 while for only AC tests, it develops into Stage 5 in all samples. Each data point on the plot is the average value of apparent charge $\left(\mathrm{Q}_{\mathrm{IEC}}\right.$-value $)$ over 1 minute. This was synchronized with the tree images as shown in Figure 6.

\subsection{PURE AC STRESS}

Stages 1 to 5 have been discussed by the authors previously [21]. Here, Stage 5 is further divided into 5.1 to 5.3 as shown in Figure 6. The example discussed is a typical discharge characteristic from an AC test. Plots for all tests examined can be obtained in [20] and are summarized as:

Stage 1; pre-initiation, prior to a visible tree. PDs were not 
recorded at this stage as trees were pre-initiated under AC in all samples to eliminate variations in initiation times.

Stage 2; growth of the initial dark tree. This stage lasted 48 minutes in the example of Figure 6. The average apparent charge during the first minute of tree growth was $\sim 1.3 \mathrm{pC}$ which decreased to $\sim 0.4 \mathrm{pC}$ and then increased to a maximum of $\sim 35 \mathrm{pC}$ in the 45 th minute. It then declined to $\sim 0.4 \mathrm{pC}$ in the next 3 minutes entering the 3 rd stage of tree growth.

Stage 3; propagation of fine tree channels. This stage is marked by quiescent discharge activity during which the tree structures generated were filamentary. Throughout the growth of filamentary tree structures the measured magnitude of apparent charge was $\sim 0.4 \mathrm{pC}$, as shown by both the PD plot and the corresponding tree image from 48 to 93 minutes.

Stage 4; darkening of fine tree channels. Discharge activity increased in magnitude up to about $1.0 \mathrm{pC}$. The periphery of the fine tree tips became darker, forming a visibly distinct region as they approached the ground electrode, as shown in Figure $3 \mathrm{~A}_{1}$. This period lasted for about 18 minutes.

Stage 5 ; reverse treeing. Reverse tree growth is marked by rising discharge activity up to $\sim 350 \mathrm{pC}$ in the period 5.1 , then decreasing to a more steady discharge activity between $\sim 0.4$ $0.6 \mathrm{pC}$ in Stage 5.2. Finally, sporadic activity lasting about 48 minutes with values between $\sim 1.3 \mathrm{pC}$ and $\sim 900 \mathrm{pC}$ culminated in sample failure in Stage 5.3 in Figure 6.

In stages when only filamentary trees were being formed, PDs were low in value and close to measurement sensitivity. Only when the filamentary tree approached the planar electrode and the tree tips became darkened did the PD magnitudes increase to about $1 \mathrm{pC}$. Afterwards a single channel, from which the reverse tree emanated, bridged to the ground electrode with rising magnitudes of PD.

Figure 7 shows the phase-resolved partial discharge (PRPD) patterns with corresponding tree images in the first 3 minutes of the reverse treeing process. In the first minute, PD activity occurs in the phase ranges $-90^{\circ}$ to $110^{\circ}$ and $160^{\circ}$ to $285^{\circ}$ with magnitudes up to $1.2 \mathrm{pC}$. A wing-like PRPD pattern develops
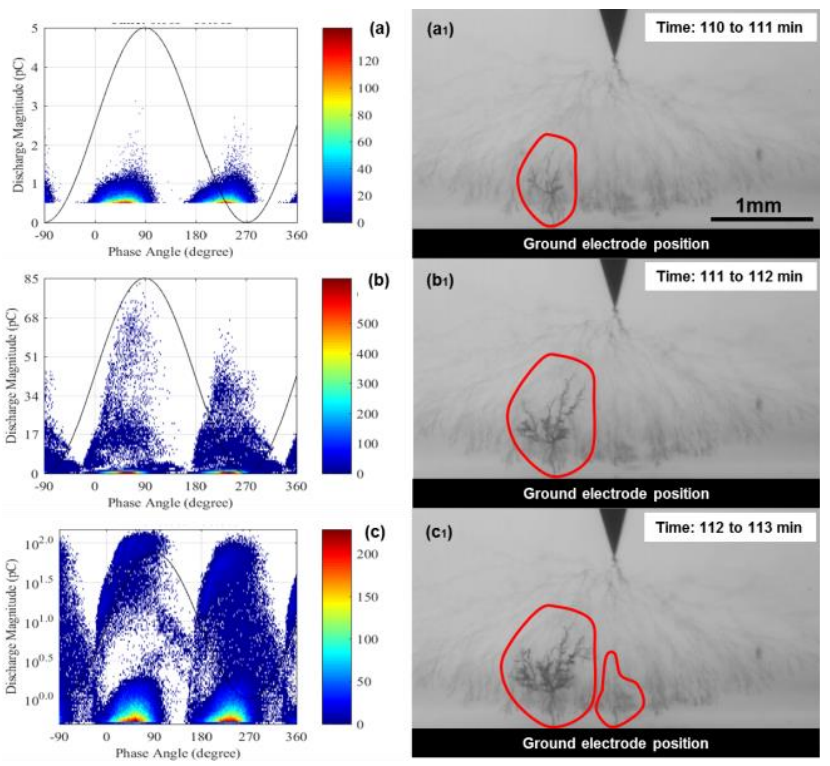

Figure 7. PRPD patterns in the early stages of reverse tree growth (highlighted by the read lines) with increasing PD magnitudes. The scale bar applies to all images. at the end of the minute and PD magnitudes increase to about 3 $\mathrm{pC}$ as shown in Figure 7a. During this period, the tree circled red in Figure $7 a_{1}$ evolved. In the second and third minutes, the wing-like PRPD patterns evolved with rising PD magnitudes of hundreds of $\mathrm{pC}$, as shown in Figure $7 \mathrm{~b}$ and $7 \mathrm{c}$. During this stage, the tree grew in the 'reverse' direction. It can be seen in Figure $7 b$ and $7 b_{1}$ that a wing-like PRPD pattern is dominant when the reverse tree is growing in length.

At the tree 'stagnation' stage, seen in region 5.2 of Figure 6 , three distinct roots from which reverse trees initiated can be clearly seen. However, further growth or changes to the tree structure was not observed during this 22 minute period. Figure 8 shows the PRPD patterns and the tree images captured at the beginning, the middle and the end of this period. Figure $8 \mathrm{a}$ and $8 \mathrm{c}$ show that very few discharges were recorded signifying the cessation of tree growth. But in Figure $8 \mathrm{~b}$, turtle-like and wing-like patterns were observed, indicating that part of the existing tree channels widened and or extended, though not visible from the focused plane images of Figure $8 \mathrm{a}_{1}, 8 \mathrm{~b}_{1}$ and $8 \mathrm{c}_{1}$.

Stage 5.3 is the final stage of the treeing process. Here erratic discharges up to about $1000 \mathrm{pC}$ were measured. This period lasted for 48 minutes, during which massive damage to the sample occurred before the final breakdown as shown in last image of Figure 6. In the final stage, several branches reached the $\mathrm{HV}$ electrode but breakdown did not occur immediately. $30 \%$ of the samples withstood the voltage for several hours although the entire sample looked severely degraded. This may be because the $10 \mathrm{M} \Omega$ resistor limited the current and thermal damage in the sample.

\subsection{SUPERIMPOSED AC AND DC VOLTAGES}

Figure 9 shows PD characteristics for two samples stressed with superimposed AC and DC voltages. For all samples, only the first four of the stages described in Figure 6 were observed. As described in the pure AC case, the apparent PD charge values for Stage 2 vary from $3 \mathrm{pC}$ to $30 \mathrm{pC}$. In Stage 3,
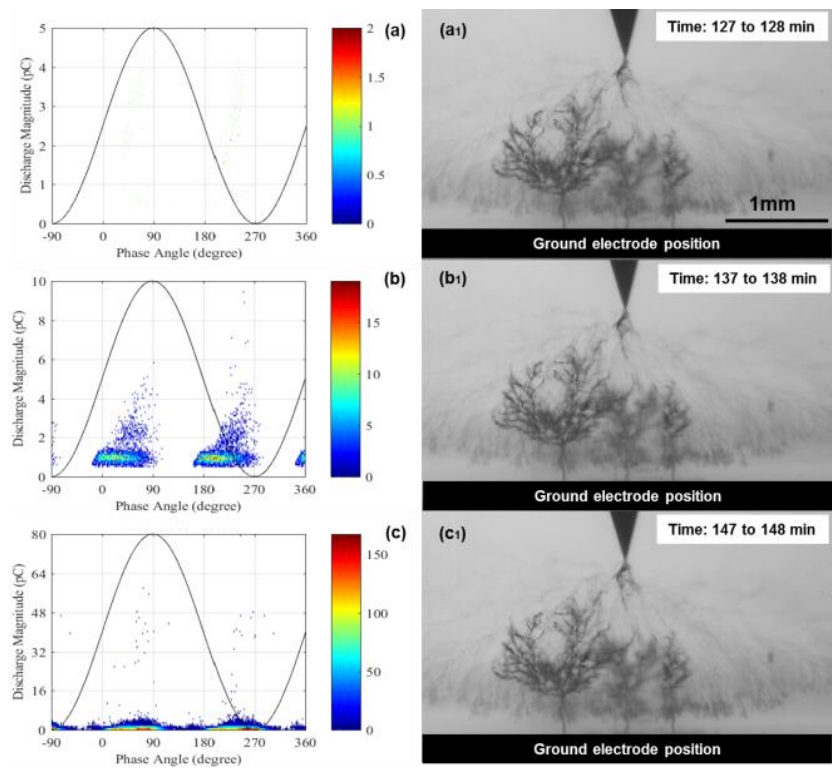

Figure 8. PRPD patterns at the start, middle and the end of electrical tree stagnation. Physical change to tree was not observed for the entire 15 minute period (figure 6). The scale bar applies to all images. 


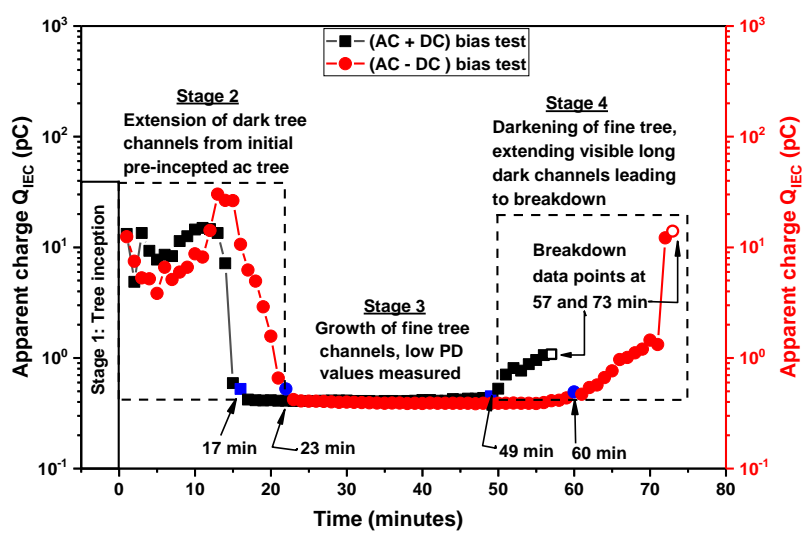

Figure 9. Partial discharge characteristics during tree.

associated with filamentary tree growth, PD were typically about $0.4 \mathrm{pC}$, close to the sensitivity of the measuring system. In Stage 4, PD magnitudes of about $0.4 \mathrm{pC}$ to $1.5 \mathrm{pC}$ were measured for positive and negative biased tests respectively.

Figure 10 shows typical PRPD patterns and the corresponding tree images at stages 2 and 4 from 8 to 9 minutes and from 55 to 56 minute for positive biased test in a particular sample. Generally the magnitudes of the apparent charge values in Stage 2 were higher than those in Stage 4 indicating different growth activity in these stages. As can be seen from Figure 10a and $10 a_{1}$ a wing-like PRPD pattern was observed when the initial dark tree channels (circled in red) grew from the pre-incepted initial tree. Afterwards, fine tree channels were propagated in the entire body of the sample with low magnitudes of $\sim 0.4 \mathrm{pC}$ or below. The PRPD pattern shown in Figure 10b is a typical example where discharges were below the sensitivity of the PD measuring system even though fine tree channels were propagating. Eventually, a tree channel became darkened with increasing PD magnitudes to $1.5 \mathrm{pC}$ as highlighted in Figure $10 \mathrm{c}$ and $10 \mathrm{c}_{1}$.

In all 20 samples, dark tree channels extended for limited distances from the initial trees at the needle in Stage 2. This was followed by arrays of fine tree channels in Stage 3 with smaller values of PD, as shown in the examples of Figure 10. In Stage 4, a few of the fine tree branches eventually darkened on approaching or touching the ground electrode with PD magnitudes increasing up to $\sim 1.5 \mathrm{pC}$. This then led to breakdown in all samples. Trees propagate faster under composite voltages than under pure $\mathrm{AC}$, resulting in reduced breakdown times in all cases.

\section{DISCUSSION}

\subsection{TREE INITIATION WITH COMPOSITE WAVEFORMS}

Steady state $\pm 30 \mathrm{kV}$ DC does not initiate electrical trees in these samples in the periods studied (>10 hours). However, with composite waveforms, if the component of power frequency voltage exceeds $10 \mathrm{kV}$, tree initiation occurs in minutes. Saito et al showed that regardless of the total voltage on the needle electrode in polyethylene, a tree is initiated only when a minimum level of about 4.7 to $5 \mathrm{kV}$ AC component is present [11]. The authors have reported in [10] that trees only initiate and propagate under higher pure DC voltages of 60 to

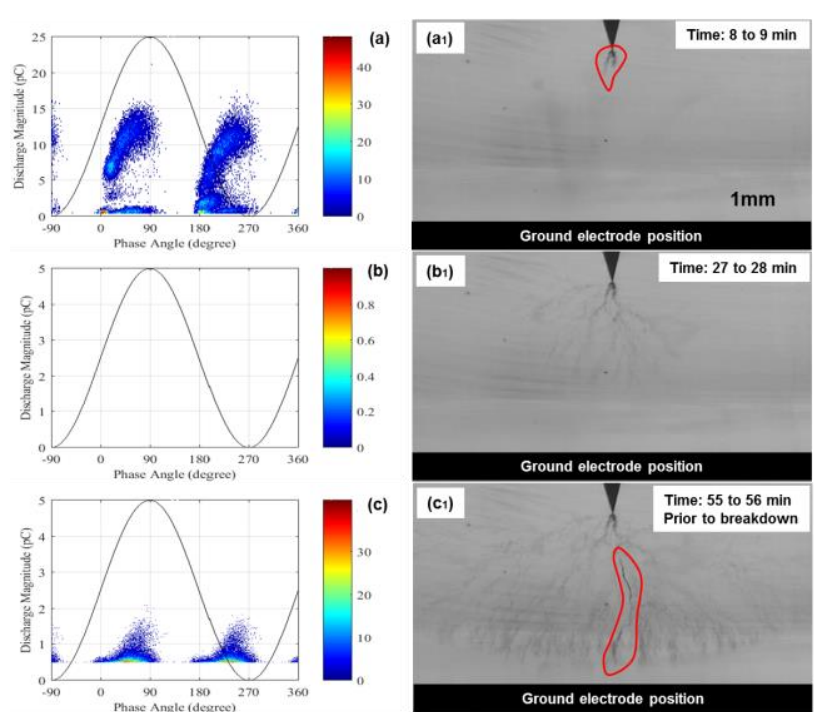

Figure 10. Partial discharge characteristics during electrical tree growth with a positive biased voltage. The scale bar applies to all images.

$70 \mathrm{kV}$. Strong polarity dependence was observed, and it was suggested that space charge plays a significant role in tree initiation, with $70 \%$ of the samples propagating to failure under positive DC whereas under negative DC very little or no propagation was observed [10]. The authors have shown that increasing the frequency of the voltage accelerates every stage of the treeing processes including tree inception, tree propagation and time to failure [9].

\subsection{TREE PROPAGATION UNDER AC AND COMBINED AC AND DC VOLTAGES}

Figure 3 shows the visual aspect of tree growth which clearly demonstrates the differences in tree growth characteristics for pure AC and combined $\mathrm{AC}$ and $\mathrm{DC}$ voltages. Although the peak-to-peak voltage used to stress each group of samples was $30 \mathrm{kV}$ as shown in Figure 2, the effective RMS values for $\mathrm{AC}$ and biased $\mathrm{DC}$ with $\mathrm{AC}$ voltages will be different. In addition, the energy gained by the injected electrons/hole from the point electrode within the insulation will be different on the application of each voltage type, and depends on the local field which comprises the point-on-wave Laplacian field and the Poisson field generated by space charge. Space charge will invariably reduce the field in a pure DC situation. For the AC case, Maxwell compression forces and/or fatigue leading to local breakdown and subsequent partial discharges may occur, due to repeated charge injection and extraction at every half cycle. For the combined AC and DC case, a combination of injected charge avalanches in one direction coupled with Maxwell stress can be considered. The scenarios in these two cases can be viewed as analogous to damage being accumulated in concrete using a drilling machine with 'rotary', and 'rotary plus hammer' settings. The analogy of the 'rotary' action having little effect on its own, just as the DC component only has little impact, whereas 'rotary plus hammer' is analogous to the combined AC and DC components of the applied voltage, where the addition of the (AC) hammering allows the rotary motion (DC) to rapidly erode the material. Figure 5 shows that adding DC voltage of either polarity to an AC signal reduces time to breakdown. The 
positive biased voltage had more impact, leading to $62 \%$ reduction of insulation lifetime compared with $54 \%$ reduction for the negative biased test compared with the AC tests. In [10], the authors have shown that for pure DC, voltage polarity has profound effect on tree propagation. This is due to the difference in charge injection under positive and negative polarity. In this study, it is shown that the AC component is the essential driver of tree growth and that the DC component accelerates tree propagation.

\subsection{PARTIAL DISCHARGES UNDER AC AND COMBINED AC AND DC VOLTAGES}

It can be observed that the PD behavior in Stages 2 to 4 are common to both $\mathrm{AC}$ and combined $\mathrm{AC}$ and DC voltages, as shown in Figure 6 and Figure 9 respectively. A complex behavior was seen under AC in Stage 5. The differences in the trend and magnitudes of the recorded apparent charges corresponded to the differences in the shapes of tree structures. For example, Stages 2 and 5.3 of Figure 6 show sporadic and higher discharge magnitudes when a dark branch-like tree structures developed at the beginning and at the end of the life cycle of the tree. However, when the fine tree tips darkened or the tree stagnated or the channels widened/darkened, moderate discharge magnitudes were observed as shown in Stages 4 and 5.2 of Figure 6, and Stage 4 of Figure 9. Although the trees accelerated under combined AC and DC leading to shorter breakdown times, neither PD magnitudes nor PRPD patterns were markedly different.

Previously, DC voltages did not show any detectable discharges [22], and it was concluded that there was no evidence for a direct relation between PD and breakdown. From the results presented here, it is shown that irrespective of the voltage type (AC or $\mathrm{AC} \pm \mathrm{DC}$ ), wing-like PRPD patterns with high magnitudes of PDs were related to development of dark tree channels growing in length, either in the forward direction (Figure $10 \mathrm{a}$ and $10 \mathrm{a}_{1}$ ) or in the reverse direction (Figure 7). But turtle-like PRPD patterns or clustering of PDs with lower discharge magnitudes were observed only when tree channels are widening or the tree tips are darkening, (Figure 10c and $10 c_{1}$ ). Different discharge characteristics responded to different tree developments and the fine tree channels propagated only when discharge magnitudes of $\sim 0.4$ $\mathrm{pC}$ or lower were recorded. The PD response during tree growth is similar to the observation by Chen et al [23]. When very low PD magnitudes were recorded, dark tree branches stopped growing, and only short spiky tree branches were observed growing along the main channel of tree branches. In this study, fine tree channels grew continuously, and dark tree branches stopped growing, conditions which can be differentiated by PD characteristics.

In Stage 4 rising PD magnitudes were observed (see Figures 6 and 9) when the fine tree channels approached the counter electrode. Those from AC tests formed dense and dark bushlike structure at the periphery, while those from $\mathrm{AC} \pm \mathrm{DC}$ tests developed long visible widened dark channels, as shown in the images of Figure $3 \mathrm{~A}_{1}$ and $3 \mathrm{~B}_{2}$ respectively.

Two areas at different stages experienced high electric fields: Firstly at the vicinity of the point electrode, rising PD magnitudes were observed due to channel degradation and erosion, leading to the dark tree extensions of tree seen in
Stage 2, as shown in Figure 6 and Figure 10a respectively. Secondly, when the tree channels approached the ground electrode, again the electric field intensified, due to an effectively reduced insulation gap resulting in rising PD magnitudes, as shown in Stage 4 of Figure 6 and Figure 10c. Here the electric field near the needle electrode drops, while the electric field at the tree tips intensifies [7-8]. At this stage, tree tips darkened in all samples under AC tests, after which reverse trees emanated with increased discharge activity leading to sample breakdown. For $\mathrm{AC} \pm \mathrm{DC}$ tests, long and widened dark channels were observed in all samples with increasing PD activity leading to sample breakdown.

\section{CONCLUSIONS}

This study shows that electrical tree growth is accelerated by the combined effect of DC and power frequency AC. This suggests that mixed $\mathrm{AC}$ and $\mathrm{DC}$ will be more detrimental to the reliability of insulation especially in DC networks. The following specific conclusions are drawn:

- In composite voltage situations, the AC component is the essential driver of tree growth and the DC component can accelerate propagation.

- Adding DC to AC stress reduced the breakdown times. Statistical analysis (Student t-test) shows that there is greater than $95 \%$ chance that the difference between the means of the polarities is significant, the positive having more impact.

- The impact of positive DC bias is more significant than negative DC bias. This is consistent with treeing under pure DC conditions in which positive DC is more aggressive than the negative DC polarity.

- Tree initiation using combined AC and DC voltages is driven by the magnitude of the $\mathrm{AC}$ component in the composite waveform.

- Different tree structures and stages of development generate different PD characteristics, with thick and dark tree branches resulting in magnitudes of $1 \mathrm{pC}$ to about $1 \mathrm{nC}$ whereas fine tree channels resulted in PD magnitudes of $0.4 \mathrm{pC}$ or less.

\section{ACKNOWLEDGMENT}

The authors are grateful to the EPSRC for support through the projects 'Towards Enhanced HVDC Cable Systems', EP/L021560/1, and 'HubNet: Research Leadership and Networking for Energy Networks', EP/N030028/1.

This paper contains data which is openly available from www.manchestertrees.com.

\section{REFERENCES}

[1] L. A. Dissado and J. C. Fothergill, Electrical Degradation and Breakdown in Polymers. London, U.K.: Peter Perengrinus Ltd., 1992.

[2] K. Wu, Y. Suzuoki, T. Mizutani, and H. Xie, "A novel physical model for partial discharge in narrow channels," IEEE Trans. Dielectr. Electr. Insul., vol. 6, pp. 181-190, 1999.

[3] J. V. Champion, S. J. Dodd, and J. M. Alison, "The correlation between the partial discharge behaviour and the spatial and temporal development of electrical trees grown in an epoxy resin," J. Phys. D. Appl. Phys., vol. 29, p. 2689, 1996.

[4] R. Schurch, S. M. Rowland, and R. S. Bradley, "Partial discharge energy and electrical tree volume degraded in epoxy resin," in Ann. Rep. IEEE Conf. Electr. Insul. Dielectr. Phenom., 2015, pp. 820-823.

[5] K. Wu, Y. Suzuoki, T. Mizutani, H. Xie, "Model for partial discharges 
associated with treeing breakdown: III. PD extinction and regrowth of tree,” J. Phys. D. Appl. Phys., vol. 33, pp. 1209-1218, 2000.

[6] Z. Lv, S. Rowland, S. Chen, H. Zheng, and I. Iddrissu, "Evolution of partial discharges during early tree propagation in epoxy resin," IEEE Trans. Dielectr. Electr. Insul., vol. 24, pp. 2995-3003, 2017.

[7] J. V. Champion, S. J. Dodd, G. C. Stevens, "Analysis and modelling of electrical tree growth in synthetic resins over a wide range of stressing voltage,” J. Phys. D. Appl. Phys., vol. 27, pp. 1020-1030, 1994.

[8] G. Chen and C. Tham, "Electrical treeing characteristics in XLPE power cable insulation in frequency range between 20 and $500 \mathrm{~Hz}$," IEEE Trans. Dielectr. Electr. Insul., vol. 16, pp. 179-188, 2009.

[9] I. Iddrissu and S. M. Rowland, "The Impact of Harmonic Frequencies in Annu. Rep. Conf. Electr. Insul. Dielectr. Phenom., 2017, pp. 753-756.

[10] I. Iddrissu, H. Zheng, and S. M. Rowland, "DC Electrical Tree Growth in Epoxy Resin and the Influence of the Size of Inceptive AC Trees," IEEE Trans. Dielectr. Electr. Insul., vol. 24, pp. 1965-1972, 2017.

[11] Y. Saito, M. Fukuzawa, and H. Nakamura, "On the Mechanism of Tree Initiation,” IEEE Trans. Electr. Insul., vol. 12, pp. 31-34, 1977.

[12] F. Mauseth, M. Amundsen, A. Lind, H. Faremo, "Water tree growth of wet XLPE insulation stressed with DC and high frequency AC," in Annu. Rep. IEEE Conf. Electr. Insul. Dielectr. Phenom., 2012, pp. 692695.

[13] G. Mazzanti, G. Passarelli, A. Russo, and P. Verde, "The effects of voltage waveform factors on cable life estimation using measured distorted voltages," in Proc. IEEE Power Eng. Society General Meeting, 2006, pp. 1-8.

[14] S. Bahadoorsingh and S. M. Rowland, "Investigating the Impact of Harmonics on the Breakdown of Epoxy Resin through Electrical Tree Growth," IEEE Trans. Dielectr. Electr. Insul., vol. 17, pp. 1576-1584, 2010.

[15] Recommended Practices and Requirements for Harmonic Control in Electrical Power Systems, IEEE Standard 519-1992 992.

[16] I. Iddrissu and S. M. Rowland, "The Impact of DC Bias on Electrical Tree Growth Characteristics in Epoxy Resin Samples," in Annu. Rep. IEEE Conf. Electr. Insul. Dielectr. Phenom., 2015, pp. 876-879.

[17] S. Bahadoorsingh, "Asset Management and the Role of Power Quality on Electrical Treeing in Epoxy Resin," PhD Thesis, The University of Manchester, Manchester United Kingdom, 2009.

[18] High-voltage test techniques - Partial discharge measurements, British Standard (BS EN 60270:2001)

[19] I. Iddrissu, H. Zheng, and S. M. Rowland, "Electrical tree growth in epoxy resin under DC voltages," in Proc. IEEE Int. Conf. Dielectr., 2016, pp. 820-823.

[20] I. Iddrissu, "Study of Electrical Strength and Lifetimes of Polymeric Insulation for DC Applications.," PhD Thesis, (https://www.research.manchester.ac.uk/portal/files/54587825/FULL_T EXT.PDF) The University of Manchester, 2016.

[21] I. Iddrissu, Z. Lv, and S. M. Rowland, "The dynamic character of partial discharge in epoxy resin at different stages of treeing," in Proc. IEEE Int. Conf. Dielectr., 2016, pp. 728-731.

[22] P. H. F. Morshuis and J. J. Smit, "Partial discharges at dc voltage: Their mechanism, detection and analysis," IEEE Trans. Dielectr. Electr. Insul., vol. 12, pp. 328-340, 2005.

[23] X. Chen, Y. Xu, X. Cao, S. J. Dodd, and L. A. Dissado, "Effect of tree channel conductivity on electrical tree shape and breakdown in XLPE cable insulation samples,” IEEE Trans. Dielectr. Electr. Insul., vol. 18, pp. 847-860, Jun. 2011.

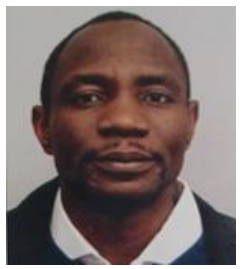

Ibrahim Iddrissu was born in Accra, Ghana. He received his BEng in Electrical and Electronic Engineering at London South Bank University in 2011. He received his $\mathrm{PhD}$ in 2016 from the University of Manchester where he is currently a Research Associate. His research interests are related to dielectric reliability (Electrical trees and partial discharge measurements) for HVDC application.

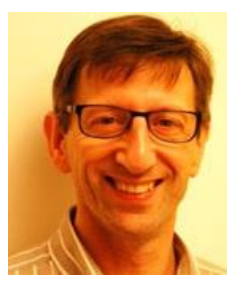

Simon M. Rowland (F '14) graduated in physics at The University of East Anglia, and gained a PhD at London University. He has worked in commercial research for many years on dielectrics and their applications. He joined The School of Electrical and Electronic Engineering in The University of Manchester in 2003, and was appointed Professor of Electrical Materials in 2009, and Head of School in 2015. He was President of the IEEE Dielectric and Electrical Insulation Society from 2011-12.

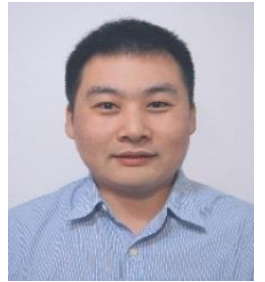

Hualong ZHENG was born in Henan, China. He received a B.Eng. in Electrical Engineering and Automation from Changsha University of Science \& Technology in 2010, an MSc in Electrical Power Systems Engineering from The University of Manchester in 2011, and a PhD from the University of Leicester in 2015. He is currently a Research Associate at the University of Manchester. His research interests lie in space charge phenomena in polymeric DC insulation.

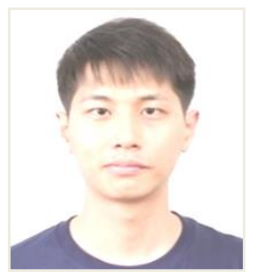

Zepeng $\mathbf{L v}$ received the B.S. degree in electrical engineering from Xi'an Jiaotong University, Xi'an, China, in 2009; and then he received his doctoral degree from the same university in 2015 . Now he works as a post-doctoral research associate in School of Electrical and Electronic Engineering, The University of Manchester. His research interests are in charge transport and aging processes in dielectrics.

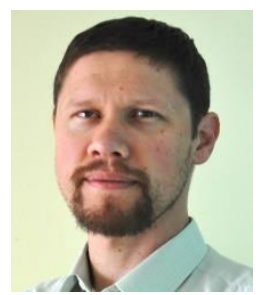

Roger Schurch (S'11, M'15) was born in Temuco, Chile. He received the degree in electrical engineering in 2006 from Federico Santa Maria Technical University (UTFSM). He was a high voltage equipment analyst at Transelec transmission company, before joining, UTFSM, as Lecturer in 2008. He completed his $\mathrm{PhD}$ in 2014 at The University of Manchester and re-joined the Department of EE (UTFSM) as Assistant Professor. 